\title{
The effects of hepatitis $C$ virus non-structural protein 3 on cell growth mediated by extracellular signal-related kinase cascades in human hepatocytes in vitro
}

\author{
BO LI ${ }^{1 *}$, XIANG LI $^{1 *}$, YINGXIN LI ${ }^{2}$, HUI GUO ${ }^{1}$, SHU-YAN SUN ${ }^{1}$, QIONG-QIONG HE ${ }^{1}$, \\ YING WANG $^{1}$, JUNMING LUO ${ }^{3,4}$, JI-FANG WEN ${ }^{1}$, HUI ZHENG ${ }^{1}$ and DE-YUN FENG ${ }^{1}$
}

${ }^{1}$ Department of Pathology, Xiangya School of Medicine, Central South University, Changsha 410013, P.R. China; ${ }^{2}$ Eshelman School of Pharmacy, University of North Carolina, Chapel Hill, NC 27599; ${ }^{3}$ AmeriPath, Kansas City, MO 64137, USA;

${ }^{4}$ Department of Pathology, The Second Xiangya Hospital, Central South University, Changsha 410013, P.R. China

Received March 8, 2010; Accepted April 19, 2010

DOI: $10.3892 /$ ijmm_00000462

\begin{abstract}
Hepatitis C virus (HCV) infection has become a severe health problem worldwide. The viral proteins are believed to be among the most important factors that contribute to $\mathrm{HCV}$ mediated pathogenesis. Accumulated evidence demonstrating that HCV non-structural protein 3 (NS3) possesses oncogenic potential, and is involved in the regulation of cell proliferation has been documented. In this study, we emphasized the effect of HCV NS3 protein on cell proliferation in the immortally normal hepatocyte QSG7701 cells. The cell line transfected with plasmid expressing NS3 protein showed enhanced cell growth, extracellular signal-related kinase (ERK) activation, DNA binding activities of transcription factors of activator protein 1 (AP-1) and NF-kB, and cyclin D1 overexpression, but without activation of Jun amino-terminal kinase or p38. Pre-treatment of NS3 protein expressing cells with ERK inhibitor, PD98059, blocked the activation of AP-1 and NF- $\mathrm{kB}$, and inhibited cyclin D1 expression and cell proliferation. The results suggest that NS3-mediated cell growth occurs through activation of ERK/AP-1 and NF-KB/cyclin D1 cascades.
\end{abstract}

\section{Introduction}

Hepatitis $\mathrm{C}$ is an infectious disease caused by the hepatitis $\mathrm{C}$ virus (HCV). The disease affects $\sim 200$ million people worldwide (1). HCV infections often progress to persistent infection and advance to severe liver injury such as chronic hepatitis $\mathrm{C}$, liver cirrhosis and primary hepatocyte carcinoma (HCC) when

Correspondence to: Dr De-yun Feng, Department of Pathology, Xiangya School of Medicine, Central South University, 172 Tongzipo Road, Changsha 410013, Hunan Province, P.R. China

E-mail: dyfeng743@yahoo.com.cn

*Contributed equally

Key words: hepatitis C virus non-structural protein 3, extracellular signal-related kinase, activator protein 1 , nuclear factor- $\mathrm{k}$, cell growth the immune system of acute $\mathrm{HCV}$-infected patients fails to clear the virus or responds poorly to antiviral therapy (2).

$\mathrm{HCV}$ is an enveloped, single-stranded positive-sense RNA virus that belongs to the family Flaviviridae. The 9.6-kb viral genome encodes a precursor polyprotein of $\sim 3,010$ amino acids, which is cleaved by both the cellular and viral proteases into at least 4 structural proteins (core, E1, E2 and p7) and 6 non-structural proteins (NS2, NS3, NS4A, NS4B, NS5A, and NS5B).

Non-structural protein 3 (NS3) possesses serine protease activity, which is important for viral protein processing (3), and nucleotide triphosphatase-RNA helicase activity, which is essential for virus replication (4-7). Besides its pivotal role in viral protein processing and virus replication, the HCV NS3 protein was reported to be involved in malignant transformation of NIH3T3 cells (8). Our previous study also showed the oncogenic potential of HCV NS3 N terminal protein (9).

In our previous study, we found that HCV NS3 N terminal protein can activate the mitogen-activated (MAPK) signaling pathway extracellular signal-related kinase (ERK) in the immortally normal hepatocyte QSG7701 cells (10), which might have been involved in the stimulation of cell growth $(11,12)$. The disturbance of cell proliferation is closely associated with carcinogenesis. However, the refined mechanisms of this regulation remain to be determined. HCV NS3 N terminal protein and the whole HCV NS3 protein might possess a different biological manner. To address this problem, the normal human hepatocyte cell line QSG7701 was used in this study. The results showed that the cell transfected the whole HCV NS3 protein, promoting cell growth and activated ERK/activator protein 1 (AP-1) and NF-кB/cyclin D1 cascades, suggesting that the activation of ERK/AP-1 and $\mathrm{NF}-\mathrm{\kappa B} /$ cyclin D1 cascades is essential for the stimulation of HCV NS3 protein-mediated cell growth in QSG7701 cell line.

\section{Materials and methods}

Cell culture. The human hepatocyte cell line QSG7701 was obtained from the Cell Bank of Type Culture Collection of Chinese Academy of Sciences, Shanghai Institutes for Biological Sciences Chinese Academy of Sciences (Shanghai, 
China). Cells were maintained in Dulbecco's modified Eagle's medium supplemented with $10 \%$ fetal calf serum, $100 \mathrm{U} / \mathrm{ml}$ penicillin $\mathrm{G}$, and $100 \mathrm{unit} / \mathrm{ml}$ streptomycin, at $37^{\circ} \mathrm{C}$ in a humidified atmosphere of $5 \% \mathrm{CO}_{2}$. All cell culture reagents were from Gibco BRL (Carlsbad, USA).

Plasmid construction. The HCV cDNA p90HCVconFLlongpU (13) was kindly provided by Professor Charles M. Rice (Department of Molecular Microbiology, Washington University School of Medicine, St. Louis, MO). The nonexpressive plasmid pcDNA3.1(+) was purchased from Invitrogen (Groningen, The Netherlands). The sense primer

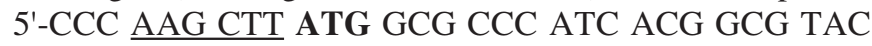
G-3' contains a start codon (bold) and a HindIII restriction site (underlined), and the anti-sense primer 5'-CG GGA TCC TTA CGT GAC GAC CTC CAG GTC GG-3' includes a stop codon (bold) and a BamHI restriction site (underlined). These primers were used to amplify the cDNA encoding regions of HCV NS3 (nt 3340-5244, gene bank \#AF009606). The amplified PCR products were digested by HindIII and BamHI, and then cloned into pcDNA3.1(+) to generate pcDNA3.1-NS3 plasmid.

Transfection and selection of cell strains with stable expression of HCV NS3 protein. DMEM culture medium with $10 \%$ fetal calf serum was used to culture QSG7701 cells in 12-well cell culture plates until cells covered $90-95 \%$ of the area. Serum-free DMEM was used for culture overnight. Transfection of cell lines was conducted with a Lipofectamine 2000 liposome transfection kit. According to the directions of the manufacturer, liposome and plasmid pcDNA3.1-NS3 were mixed and added to each well. pcDNA3.1 empty vector transfection group and blank control group (only liposome was added, but no vector DNA) were established. Transfection was completed after $24 \mathrm{~h}$ incubation. Transfected cells were diluted then selected in medium containing $400 \mu \mathrm{g} / \mathrm{ml} \mathrm{G} 418$. The selection process lasted 31 days to allow colony formation. Colonies resistant to $\mathrm{G} 418$ were isolated with cloning cylinders and transferred into 24-well dishes. Ten positive clones were obtained from the plasmid pcDNA3.1-NS3 transfection group (pcDNA3.1-NS3/QSG) and 3 positive clones were obtained from the pcDNA3.1 empty vector transfection group (pcDNA3.1/QSG) in QSG7701 cells. The clones (pcDNA3.1-NS3/QSG) constitutively expressing HCV NS3 protein were validated by reverse transcription polymerase chain reaction (RT-PCR) and Western blot analysis. QSG7701 cells were also transfected with the non-expression vector pcDNA3.1(+) as a negative control (pcDNA3.1/QSG). QSG7701 parental cells were used for the parallel control.

Experimental groups. Experimental groups include 3 clones expressing HCV NS3 protein, 1 clone transfected with empty plasmid pcDNA3.1 and QSG7701 parental cells. Group 1-3, QSG7701 transfected with plasmid pcDNA3.1-NS3 (QSG7701/NS3-1, 2, 3); 4, QSG7701 transfected with empty plasmid pcDNA3.1 (QSG7701/pcDNA3.1); 5, QSG7701 parental cells.

$R T$-PCR. Total cellular RNA was extracted from the cell line with Trizol reagent (Gibco/BRL) and quantified by UV absorbance spectroscopy. The reverse transcription reaction was performed using Takara RNA PCR kit (AMV) Ver. 3.0 (Dalian, China). The newly synthesized cDNA was amplified by PCR (Takara). Primers involved were, the HCV NS3 gene (nt4506-5181) primer (forward, 5'-AGA CAT CTC ATC TTC TGC CAC TCA AA-3; reverse, 5'-GGC GGA TCA AAC ACT TCC ACA TC-3'); ß-actin primer (forward, 5'-TGA CGG GGT CAC CCA CAC TGT GCC CAT CTA-3'; reverse, 5'-CTA GAA GCA TTT GCG GTG GAC GAT GGA GGG-3'). Amplified PCR products were 676 and $661 \mathrm{bp}$ for HCV NS3 and $\beta$-actin, respectively. Conditions for PCR were as follows, $95^{\circ} \mathrm{C}$ pre-denaturation for $5 \mathrm{~min}, 95^{\circ} \mathrm{C}$ denaturation for $30 \mathrm{sec}, 58^{\circ} \mathrm{C}$ annealing for $30 \mathrm{sec}, 72^{\circ} \mathrm{C}$ extension for $1 \mathrm{~min}$ for 35 cycles followed by $72^{\circ} \mathrm{C}$ for $10 \mathrm{~min}$. Aliquots of the PCR product were electrophoresed on $1.5 \%$ agarose gels and PCR fragments were visualized by UV illumination (UVP GDS7500 Gel, Upland, CA, USA) stained by ethidium bromide. The fluorescence intensity of $\beta$-actin fragments served as the criterion for the HCV NS3 fragments. Densitometric analysis was performed using the electrophoresis image analysis system Smart View 2000 software (Furi, Shanghai, China).

Western blotting. Western blot analysis was performed with collected cell lysate as described before (12). Collected samples were mixed with standard 2x SDS reducing gelloading buffer containing 5\% ß-mercaptoethanol. Samples were boiled for $10 \mathrm{~min}$ before loaded onto 4-15\% SDS-PAGE gels. After electrophoresis, proteins were transferred onto an Immobilon-PVDF membrane (Millipore Corp., Bedford, MA) in $25 \mathrm{mM}$ Tris, $192 \mathrm{mM}$ glycine, and $15 \%$ methanol. The membranes were blocked in 5\% non-fat milk (Bio-Rad) in PBS for $2 \mathrm{~h}$ and then probed with antibodies. Antibodies were used at the following dilutions and obtained from the indicated sources, anti-HCV NS3 antibody diluted 1:1,000 (Santa Cruz Biotechnology, Santa Cruz, USA); anti-p44/42 MAPK antibody diluted 1:1,000 (\#9102, Cell Signaling); anti-phospho-p44/42 MAPK antibody diluted 1:1,000 (\#9101, Cell Signaling), anti-p38 MAPK antibody diluted 1:1,000 (Sc-7972, Santa Cruz Biotechnologies), and anti-phospho-p38 MAPK diluted 1:1000 (Sc-7973, Santa Cruz Biotechnologies), anti-SAPK/Jun amino-terminal kinase (JNK) MAPK antibody diluted 1:1,000 (\#9252, Cell Signaling); anti-phospho-SAPK/ JNK MAPK antibody diluted 1:1,000 (\#9251, Cell Signaling); anti-cyclin D1 antibody diluted 1:1,000 (NewMarker). AntiB-actin antibody $(1: 2,000$, Santa Cruz Biotechnology) was used as a loading control. Horseradish peroxidase conjugated goat anti-mouse or goat anti-rabbit $\operatorname{IgG}(\mathrm{H}+\mathrm{L})$ (Bio-Rad Laboratories, Melville, NY), diluted 1:5,000, was used as a secondary antibody. Visualization of immunoreactive proteins was achieved by using the ECL Western blotting detection reagents (Amersham Corp., Heights, IL) and the membrane was exposed to a Kodak X-Omat AR film. Molecular weights of the immunoreactive proteins were determined using two different sets of protein marker ladders. All experiments were performed at least three times.

Preparation of nuclear extracts. Cells were harvested at the indicated time points and nuclear extracts were prepared. Unless indicated otherwise, all procedures were performed at 
A

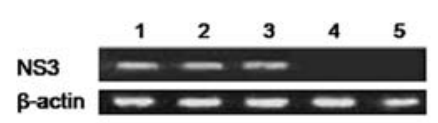

B

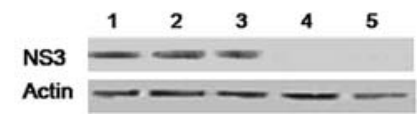

Figure 1. HCV NS3 protein expression in QSG7701 cells. (A) RT-PCR analysis of the expression of HCV NS3. (B) Western blot analysis of the expression of HCV NS3. Lane 1, QSG7701/NS3-1; 2, QSG7701/NS3-2; 3, QSG7701/NS3-3; 4, QSG7701/pcDNA3.1; 5, QSG7701.

4- $8^{\circ} \mathrm{C}$. Briefly, cells were washed with ice-cold PBS buffer and harvested by the addition of $500 \mu \mathrm{l}$ of buffer A $(10 \mathrm{mM}$ HEPES, pH 7.9, $10 \mathrm{mM} \mathrm{KCl,} 0.1 \mathrm{mM}$ EDTA, 0.1 mM EGTA, $1 \mathrm{mM}$ DTT, $0.5 \mathrm{mM}$ PMSF) containing protease inhibitor and incubated on ice for $10 \mathrm{~min}$. The supernatant was discarded after centrifugation at $14,000 \mathrm{rpm}$ for $3 \mathrm{~min}$. The pellet was resuspended in $50 \mu \mathrm{l}$ of buffer $\mathrm{C}$ (20 mM HEPES, pH 7.9, $0.42 \mathrm{M} \mathrm{NaCl}, 1 \mathrm{mM}$ EDTA, $1 \mathrm{mM}$ EGTA, $1 \mathrm{mM}$ DTT, $1 \mathrm{mM}$ PMSF) containing protease inhibitor and incubated for $20 \mathrm{~min}$ at $4^{\circ} \mathrm{C}$ and then centrifuged at $14,000 \mathrm{rpm}$ for $3 \mathrm{~min}$. The supernatant containing nuclear protein was quantified by BCA protein assay kit and stored at $-70^{\circ} \mathrm{C}$.

Electrophoretic mobility shift assays (EMSA). The operating procedures of EMSA were according to the LightShift Chemiluminescent EMSA Kit (\#20148, Pierce Biotechnologies) protocol. Specific oligonucleotides for binding of AP-1 (S, 5'-CGC TTG ATG AGT CAG CCG GAA-3'; A, 3'GCG AAC TAC TCA GTC GGC CTT-5'), and NF-кB (S, 5'AGT TGA GGG GAC TTT CCC AGG C-3'; A, 3'-TCA ACT CCC CTG AAA GGG TCC G-5') were prepared by end labeling of the 5'-terminus with Biotin (synthesized by Bioasia Biotech, Shanghai, China). Three independent experiments were performed.

MTT cell proliferation assay. MTT assay was used to analyse cell proliferation in the sample. Cells were seeded on 96-well plates at a predetermined optimal cell density to ensure exponential growth in the duration of the assay. After incubation for $72 \mathrm{~h}, 20 \mu \mathrm{l}$ MTT (5 g/l) was added to each well and the plate was incubated at $37^{\circ} \mathrm{C}$ for $4 \mathrm{~h}$. Then all culture medium supernatant was removed from wells and replaced with $100 \mu$ l DMSO. Plates were shaken for $15 \mathrm{~min}$. All formation production induced by MTT was dissolved. Then, a microplate reader at $492 \mathrm{~nm}$ measured the absorbance in each well. The inhibition of cell growth was calculated by the equation, growth inhibitory rate $=(1-$ A492 treated/A492 control) $\mathrm{x} 100 \%$. The experiment was repeated three times.

Flow cytometry. Cells were seeded at a density of $2 \times 10^{5}$ cells per 100-mm culture dish and covered with $5 \mathrm{ml}$ of PrEGM. After $24 \mathrm{~h}$, the medium was replaced. Flow cytometry was used to analyse the cell cycle in the sample. Cells were seeded at a density of $2 \times 10^{5}$ cells per $100-\mathrm{mm}$ culture dish to ensure exponential growth for the duration of the assay. After incubation for $72 \mathrm{~h}$, cells were washed in PBS 3 times and collected. For flow cytometry analysis, samples were centrifuged for $5 \mathrm{~min}$ at $200 \mathrm{x} \mathrm{g}$, washed with $5 \mathrm{ml}$ of PBS and then resuspended in $1 \mathrm{ml}$ of freshly prepared staining solution
Table I. MTT analysis of cell proliferation.

\begin{tabular}{lc}
\hline Groups & OD value $\chi \pm \mathrm{s}$ \\
\hline $1, \mathrm{QSG} 7701 / \mathrm{NS} 3-1$ & $1.5063 \pm 0.06329$ \\
2, QSG7701/NS3-2 & $1.3605 \pm 0.00493$ \\
3, QSG7701/NS3-3 & $1.3670 \pm 0.07236$ \\
4, QSG7701/pcDNA3.1 & $1.1353 \pm 0.05302$ \\
5, QSG7701 & $1.1748 \pm 0.06259$ \\
\hline
\end{tabular}

$\mathrm{P}<0.05$

[propidium iodide $(1 \mathrm{~g} / \mathrm{l})$ diluted 1:50 in $0.1 \%(\mathrm{v} / \mathrm{v})$ Triton $\mathrm{X}$ 100 in PBS containing RNase A (0.2 g/l)]. The analysis was performed after $30 \mathrm{~min}$ of incubation at room temperature. Cells $(10,000)$ were analyzed for cell cycle distribution using a Becton Dickinson FACScan flow cytometer equipped with a 488-nm argon laser and CellQuest software (Becton Dickinson Immunocytometry Systems, San Jose, CA). Cell cycle distribution was analyzed by Mod-fit software (Verity Software House, Topsham, ME). The experiment was repeated three times.

Statistical analysis. Data were analyzed using the Statistical Package for Social Science (SPSS Release 11.5; SPSS Inc., Chicago, IL, USA). A P-value $<0.05$ or $<0.01$ was considered significant. Results are expressed as the mean \pm SD of data obtained in triplicate.

\section{Results}

HCV NS3 protein expression in QSG7701 cells. HCV NS3 protein expression was detected in QSG7701 cells transfected with pcDNA3.1-NS3 by RT-PCR and Western blotting. All of the three positive clones had NS3 protein expression. However NS3 did not express in pcDNA3.1 transfected and nontransfected cells (Fig. 1A and B).

Effects of HCV NS3 protein expression on cell growth. MTT was repeated 3 times and used to detect the proliferation ability of QSG7701/NS3-1, 2, 3, QSG7701/pcDNA3.1 and QSG7701 cells, respectively. The results show that proliferation ability of QSG7701/NS3 was much higher than that of QSG7701/ pcDNA3.1 and nontransfected cells $(\mathrm{P}<0.05)$, and no difference between QSG770/1pcDNA3.1 and QSG7701 cells (Table I). Cell distribution of the cell cycle was detected by FCM. Comparing to QSG7701/pcDNA3.1 and QSG7701 cells, the pcDNA3.1-NS3 transfected cells had G1 phase cells decreased and $\mathrm{S}$ phase cells increased (Table II), suggesting the QSG7701/NS3 cells have advantage in proliferation.

Effect of HCV NS3 protein on phosphorylation of MAPK. Three groups of MAPK, extracellular signal-related kinase (ERK)-1/2(P44/42 $\left.{ }^{\mathrm{MAPK}}\right)$, JNK, p38 proteins, are closely related to cell growth in mammalian cells. All of these kinases are activated by phosphorylation. As shown in Fig. 2, Western blot analysis demonstrated that HCV NS3 protein does not alter the expression of JNK, p38, or ERK in QSG7701 cell 
Table II. FCM analysis of cell cycle.

\begin{tabular}{lcc}
\hline Groups & G1 $(\%)$ & $\mathrm{S}(\%)$ \\
\hline 1, QSG7701/NS3-1 & 67.0 & 24.8 \\
2, QSG7701/NS3-2 & 70.5 & 21.4 \\
3, QSG7701/NS3-3 & 67.1 & 21.8 \\
4, QSG7701/pcDNA3.1 & 77.0 & 13.9 \\
5, QSG7701 & 81.4 & 11.5 \\
\hline
\end{tabular}

$\mathrm{P}<0.01$

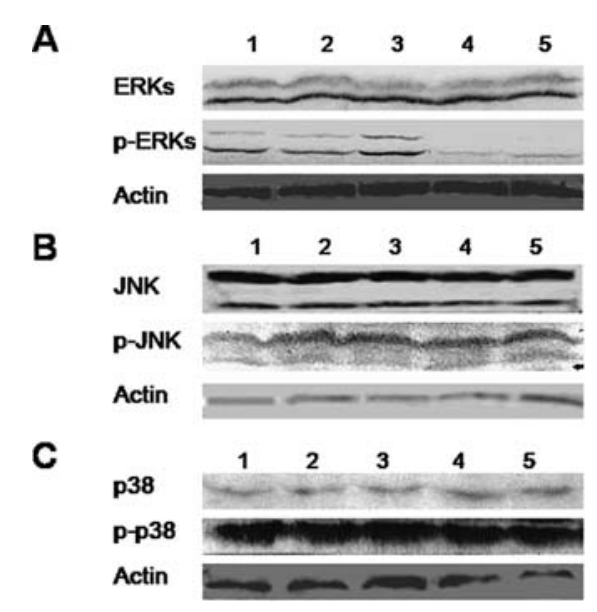

Figure 2. Effects of HCV NS3 protein on the expression and phosphorylation of JNK, p38, and ERK. Western-blotting analysis of the expression and phosphorylation of ERK (A), JNK (B) and p38 (C) in QSG7701/NS3-1, 2, 3, QSG7701/pcDNA3.1 and QSG7701 cells. The same blots were re-probed with an anti-actin antibody to compare loading and transfer. These results are representative of three independent experiments. Lane 1, QSG7701/NS3-1; 2, QSG7701/NS3-2; 3, QSG7701/NS3-3; 4, QSG7701/pcDNA3.1; 5, QSG7701.

clones. However the phosphorylation level of ERK was higher in QSG7701/NS3 cells than in QSG7701/pcDNA3.1 or QSG7701 cells. In contrast there was no change in the phosphorylation of p38 or JNK. These observations suggest that HCV NS3 expression has no effect on the basal expression of MAPK, but mediates the activation of ERK through inducing phosphorylation, which may be important for the stimulation of HCV NS3 protein-mediated cell growth.

Detecting the DNA binding activity of $A P-1$ and $N F-\kappa B$, and the expression of cyclin D1 protein. As an important downstream effector of ERK, AP-1 regulates directly the expression of cyclin D1 to affect the progress of the cell cycle. Signal transcription factor NF- $\mathrm{\kappa B}$ is an important modulator of cell proliferation. To elucidate further the mechanism of the HCV NS3 protein-mediated cell growth, we detected the DNA binding activity of AP-1 and NF- $\mathrm{KB}$, and the expression of cyclin D1 protein. EMSA analysis demonstrated that the DNA binding activity of AP-1 (Fig. 3A) and NF-kB (Fig. 3B) in QSG7701/NS3 cells were much higher than that in QSG7701/pcDNA3.1 and QSG7701 cells. Meanwhile, the
A

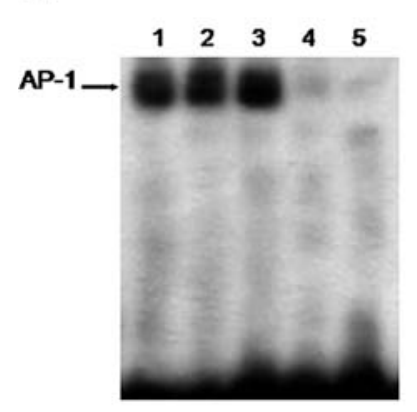

B

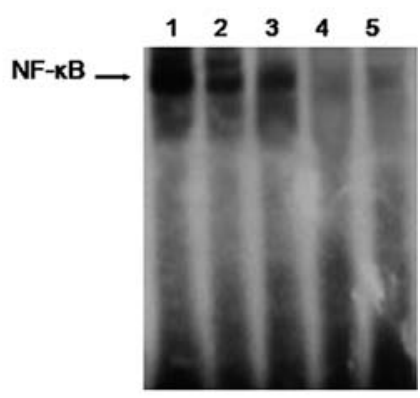

C

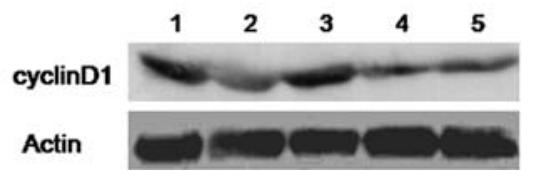

Figure 3. Effects of HCV NS3 protein on the DNA binding activity of AP-1 and NF-кB, and the expression of cyclin D1 protein. Nuclear extracts were prepared and equal amounts of nuclear proteins $(6 \mu \mathrm{g})$ were analyzed for the activity of AP-1 (A) and NF-кB (B). Western blot analysis of the expression of cyclin D1 (C) in QSG7701/NS3-1, 2, 3, QSG7701/pcDNA3.1 and QSG7701 cells. The same blots were re-probed with an anti-actin antibody to compare loading and transfer. These results are representative of three independent experiments. Lane 1, QSG7701/NS3-1; 2, QSG7701/NS3-2; 3, QSG7701/NS3-3; 4, QSG7701/pcDNA3.1; 5, QSG7701.

results of Western blotting showed that cyclin D1 (Fig. 3C) protein expression was also up-regulated in QSG7701/NS3 cells. These results suggest the stimulation of HCV NS3 protein-mediated cell growth may employ the activation of AP-1 and NF-кB/cyclin D1.

ERK inhibitor, PD98059, prevents activation of AP-1 and $N F-\kappa B$, and the expression of cyclin D1 protein, and cell growth advantage induced by HCV NS3 protein. ERK inhibitor, PD98059, specifically inhibits the activation of ERK (Fig. 4A). In order to determine whether the activation of ERK by HCV NS3 protein, is directly associated with the induced cell growth of QSG7701, we used PD98059 to block ERK activity and investigated the effect on HCV NS3 induced cell growth. In the inhibition experiments, one of the three QSG7701/NS3 cell clones was taken randomly as an experimental cell clone, and cells were pre-treated with PD98059 at $0,30,50$ and $100 \mu \mathrm{M}$ for $48 \mathrm{~h}$ before the evaluation of ERK activation. Results of EMSA revealed that the PD98059 inhibits HCV NS3-induced activation of AP-1 (Fig. 4B) and NF-кB (Fig. 4C), and Western blotting showed that HCV NS3-induced expression of cyclin D1 was decreased (Fig. 4D). MTT (Fig. 4E) and FCM (Table III) analysis illustrated that PD98059 can down-regulate HCV NS3-induced proliferation. These results suggest that the activation of AP-1 and $\mathrm{NF}-\kappa \mathrm{B} /$ cyclin D1, which were induced to express $\mathrm{HCV}$ NS3 protein, occurs as a direct consequence of HCV-induced activation of ERK. In addition, the ability of PD98059 to inhibit the HCV NS3 protein-mediated cell growth suggests that the activation of the ERK signaling pathway is essential for stimulation of $\mathrm{HCV} \mathrm{NS3}$ protein-mediated proliferative activity. 


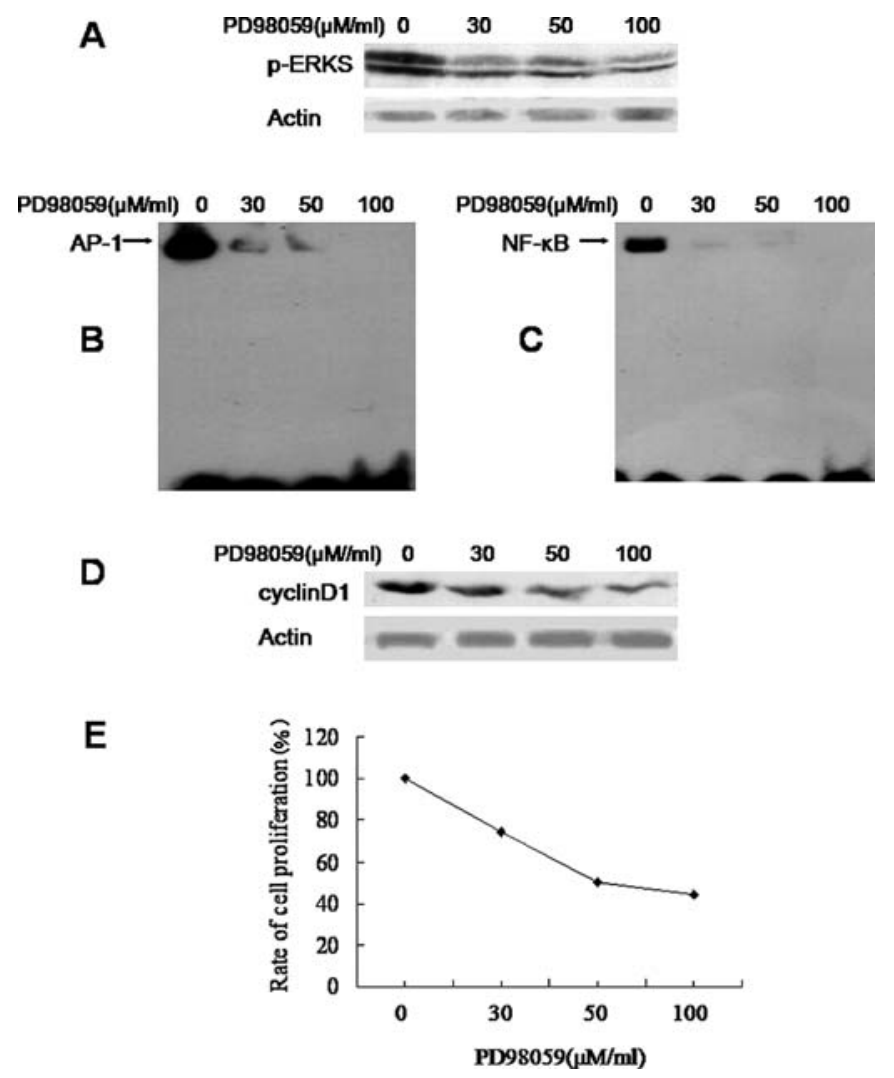

Figure 4. Inhibition of HCV NS3 protein-induced AP-1 and NF- $\mathrm{KB}$ activation, and cyclin D1 expression, and cell growth by ERKs inhibitor PD98059. One of the three QSG7701/NS3 cell clones was taken randomly as experimental cell clone, and the cells were pre-treated with PD98059 at 0,30,50 and 100 $\mu \mathrm{M}$ for $48 \mathrm{~h}$. It is shown that the ERKs inhibitor, PD98059, specifically inhibits activation of ERKs (A). The nuclear extracts were prepared and equal amounts of nuclear proteins $(6 \mu \mathrm{g})$ were analyzed for the activation of AP-1 (B) and NF- $\mathrm{KB}(\mathrm{C})$. Western blot analysis of the expression of cyclin D1 (D) The same blots were re-probed with an anti-actin antibody to compare loading and transfer. Measurement of cell growth in the presence or absence of the ERK inhibitor PD98059 was taken by MMT assay (E).

Table III. FCM analysis of cell cycle.

\begin{tabular}{lccc}
\hline Groups & PD98059 $(\mu \mathrm{M} / \mathrm{ml})$ & $\mathrm{G} 1(\%)$ & $\mathrm{S}(\%)$ \\
\hline 1 & $0 \mu \mathrm{M} / \mathrm{ml}$ & 64.6 & 22.5 \\
2 & $30 \mu \mathrm{M} / \mathrm{ml}$ & 66.8 & 20.7 \\
3 & $50 \mu \mathrm{M} / \mathrm{ml}$ & 68.7 & 19.9 \\
4 & $100 \mu \mathrm{M} / \mathrm{ml}$ & 77.6 & 13.3 \\
\hline
\end{tabular}

$\mathrm{P}<0.01 ; \mathrm{P}<0.01$

\section{Discussion}

HCV infection has become a severe health problem worldwide, but the pathogenesis of $\mathrm{HCV}$, especially the relationship between $\mathrm{HCV}$ and HCC remains to be determined. Unlike DNA virus $\mathrm{HBV}$, which can integrate its virus DNA into a host genome to cause $\mathrm{HCC}, \mathrm{HCV}$ is an RNA virus. $\mathrm{HCV}$ pathogenesis might involve its viral proteins.
The oncogenic potential of HCV NS3 protein has been well documented $(8,9,14,15)$. The disturbance of cell proliferation is closely associated with hepatocarcinogenesis. So this work emphasized the effect of HCV NS3 protein on cell proliferation. The proliferative advantage appears in the immortally normal hepatocyte QSG7701 cells expressing stably HCV NS3 protein, suggesting the potential role of $\mathrm{HCV}$ NS3 protein in the promotion of cell growth. The results provide an insight into the mechanisms of how the HCV NS3 protein mediates its oncogenic activity in infected cells and are supported by previous findings $(14,16,17)$. In addition, we also show the HCV NS3-stimulated cell growth is ERK/AP-1 cascade dependent.

Cell proliferation and apoptosis are regulated accurately by signaling cascades (18). Specifically the MAP kinase signaling cascade plays a key role in hepatocarcinogenesis $(19,20)$. Mammals express mainly three distinctly regulated groups of MAPK, extracellular signal-related kinases (ERK)-1/2, Jun amino-terminal kinases (JNK) and p38 proteins. ERK1/2 cascade is mainly correlated to cell proliferation and survival. Raf-1-mediated cell proliferation is dependent on the activation of ERK, which progresses cells from G1 phase to S phase (21). The suppression of ERK activation in fibroblasts by antisense RNA or deficient mutants could inhibit the proliferative response (22). Moreover, ERK plays a central role in the regulation of the level of p27kip1 protein, which can bind and inhibit cyclin E-Cdk2, block the G1/S transition (23). ERK can also affect the progression of the cell cycle by phosphorylation and degradation of the p27kip1 protein (24). All the information suggests that ERK is associated closely with the progression of the cell cycle. We found HCV NS3 protein induces activation of ERK signaling pathway together with the promotion of cell growth. It suggests a potential role for this pathway in the modulation of HCV NS3 protein-mediated oncogenic activity in host cells. Therefore, the ability of the ERK inhibitor to abrogate HCV NS3-induced cell growth supports that ERK activation is an essential component in the HCV NS3-stimulated cell growth.

As an important downstream effector of ERK, AP-1 regulates directly the expression of cyclin D1 to modulate the progress of the cell cycle $(25,26)$. ERK can stimulate the induction of cyclin D1 by enhancing AP-1 activity indirectly, resulting in cell proliferation (27). Silencing of AP-1 by specific antisense oligonucleotides inhibited $S$ phase entry and cell proliferation (28-30). Our results demonstrated the activation of ERK, AP-1 and its substrates cyclin D1 by HCV NS3 protein and delineated the importance of the ERK/AP-1/ cyclin D1 cascade for modulation of HCV NS3 proteinmediated cell growth. Thus, HCV NS3 protein could promote cellular proliferation for maintenance of replication and survival $(31,32)$ by this cascade and contribute to hepatocarcinogenesis.

$\mathrm{NF}-\mathrm{\kappa B}$ is a signal transcription factor that has emerged as an important modulator of altered gene programs and malignant phenotype in the development of cancer. Major carcinogens and oncogenic viruses induce NF- $\mathrm{KB}$ activation, and a variety of subsequent oncogenic events contribute to a progressive increase in constitutive $\mathrm{NF}-\kappa \mathrm{B}$ activation as an important common pathway in most forms of cancer. NF- $\mathrm{KB}$ target genes promote tumor cell proliferation, survival, 
migration, inflammation, and angiogenesis (33). Guttridge et al demonstrated NF- $\mathrm{KB}$ regulation of cyclin D1 occurs at the transcriptional level and is mediated by direct binding of $\mathrm{NF}-\kappa \mathrm{B}$ to multiple sites in the cyclin D1 promoter, which induces cyclin D1 expression and promotes G1-to-S progression (34). Moreover, the ERK substrate p90-RSK can phosphorylate IкB and induce its degradation (35), and ERK can down-regulate the expression of PAR-4, an inhibitor of $\mathrm{NF}-\kappa \mathrm{B}$ activation $(36,37)$, suggesting $\mathrm{NF}-\kappa \mathrm{B}$ activation may be regulated by ERK. In this work, ERK inhibitor, PD98059, inhibits activation of NF- $\kappa \mathrm{B}$ in the HCV NS3 expressed cell. This result indicates that, in addition to the ERK/AP-1/ cyclin D1 cascade, HCV NS3 protein-mediated cell growth also involves the ERK/NF-кB/cyclin D1 cascade as well.

HCV NS3 protein mediated cell growth in liver and in non-liver cell lines such as HepG2 and Hela, which have been demonstrated to involve the activation of JNK/AP-1 signaling pathway (16). However, different cell lines and methods were used in these two studies, which might contribute to the variation in outcomes $(38,39)$. Although different signal pathways may be involved, the potential role of HCV NS3 protein in the promotion of cell growth is consistent between our study and others.

In summary, our data demonstrate $\mathrm{HCV}$ NS3 protein can promote cell growth and contribute to hepatocarcinogenesis by the activation of ERK/AP-1 and NF-kB/cyclin D1 cascades.

\section{Acknowledgements}

We thank Professor Charles M. Rice for providing HCV cDNA p90HCVconFLlongpU. This study was supported by research grants from the National Natural Science Foundation of China (No. 30270601 and No. 30671846).

\section{References}

1. Lauer GM and Walker BD: Hepatitis C virus infection. N Engl J Med 345: 41-52, 2001.

2. Hoofnagle JH: Hepatitis C: the clinical spectrum of disease. Hepatology 26: S15-S20, 1997.

3. Grakoui A, Levis R, Raju R, Huang HV and Rice CM: A cisacting mutation in the Sindbis virus junction region which affects subgenomic RNA synthesis. J Virol 63: 5216-5227, 1989.

4. Hong Z, Ferrari E, Wright-Minogue J, Chase R, Risano C, Seelig G, Lee CG and Kwong AD: Enzymatic characterization of hepatitis $\mathrm{C}$ virus NS3/4A complexes expressed in mammalian cells by using the herpes simplex virus amplicon system. J Virol 70: 4261-4428, 1996.

5. Kim DW, Gwack Y, Han JH and Choe J: C-terminal domain of the hepatitis C virus NS3 protein contains an RNA helicase activity. Biochem Biophys Res Commun 215: 160-166, 1995.

6. Santolini E, Pacini L, Fipaldini C, Migliaccio G and Monica N: The NS2 protein of hepatitis C virus is a transmembrane polypeptide. J Virol 69: 7461-7471, 1995.

7. Suzich JA, Tamura JK, Palmer-Hill F, Warrener P, Grakoui A, Rice CM, Feinstone SM and Collett MS: Hepatitis C virus NS3 protein polynucleotide-stimulated nucleoside triphosphatase and comparison with the related pestivirus and flavivirus enzymes. J Virol 67: 6152-6158, 1993.

8. Sakamuro D, Furukawa T and Takegami T: Hepatitis C virus nonstructural protein NS3 transforms NIH 3T3 cells. J Virol 69: 3893-3896, 1995.

9. He QQ, Cheng RX, Sun Y, Feng DY, Chen ZC and Zheng H: Hepatocyte transformation and tumor development induced by hepatitis C virus NS3 c-terminal deleted protein. World J Gastroenterol 9: 474-478, 2003.

10. Zhu DH and Wang JB: The culture of HCC host hepatocyte QSG7701 cell line and as compared with hepatocarcinoma cell. Zhongliu Fangzhi Yanjiu 5: 7-9, 1979.
11. He Q, Cheng R, Chen Z, Xiao X, Xiao Z, Li C, Li B, Zhang P, Zheng $\mathrm{H}$ and Feng $\mathrm{D}$ : Cell transformation and proteome alteration in QSG7701 cells transfected with hepatitis C virus non-structural protein 3. Acta Biochim Biophys Sin 39: 751-762, 2007.

12. Feng DY, Sun Y, Cheng RX, Ouyang XM and Zheng H: Effect of hepatitis $\mathrm{C}$ virus nonstructural protein NS3 on proliferation and MAPK phosphorylation of normal hepatocyte line. World J Gastroenterol 11: 2157-2161, 2005.

13. Kolykhalov AA, Agapov EV, Blight KJ, Mihalik K, Feinstone SM and Rice CM: Transmission of hepatitis $C$ by intrahepatic inoculation with transcribed RNA. Science 277: 570-574, 1997.

14. Zemel R, Gerechet S, Greif H, Bachmatove L, Birk Y, Golan-Goldhirsh A, Kunin M, Berdichevsky Y, Benhar I and Tur-Kaspa R: Cell transformation induced by hepatitis $\mathrm{C}$ virus NS3 serine protease. J Viral Hepat 8: 96-102, 2001.

15. Zemel R, Kazatsker A, Greif F, Ben-Ari Z, Greif H, Almog O and Tur-Kaspa R: Mutations at vicinity of catalytic sites of hepatitis C virus NS3 serine protease gene isolated from hepatocellular carcinoma tissue. Dig Dis Sc 45: 2199-2202, 2000.

16. Hassan M, Ghozlan H and Abdel-Kader O: Activation of c-Jun NH2-terminal kinase (JNK) signaling pathway is essential for the stimulation of hepatitis $\mathrm{C}$ virus (HCV) non-structural protein 3 (NS3)-mediated cell growth. Virology 333: 324-336, 2005.

17. Kwun HJ, Jung EY, Ahn JY, Lee MN and Jang KL: P53dependent transcriptional repression of $\mathrm{p} 21$ (waf 1) by hepatitis C virus NS3. J Gen Virol 82: 2235-2241, 2001.

18. Wada $\mathrm{T}$ and Penninger JM: Mitogen-activated protein kinases in apoptosis regulation. Oncogene 23: 2838-2849, 2004.

19. Ito Y, Sasaki Y, Horimoto M, Wada S, Tanaka Y, Kasahara A, Ueki T, Hirano T, Yamamoto H, Fujimoto J, Okamoto E, Hayashi $\mathrm{N}$ and Hori M: Activation of mitogen-activated protein kinases/extracellular signal-regulated kinases in human hepatocellular carcinoma. Hepatology 27: 951-958, 1998.

20. Schmidt CM, McKillop IH, Cahill PA and Sitzmann JV: Increased MAPK expression and activity in primary human hepatocellular carcinoma. Biochem Biophys Res Commun 236: 54-58, 1997.

21. Sewing A, Wiseman B, Lloyd A, et al: High-intensity Raf signal causes cell cycle arrest mediated by p21Cip1. Mol Cell Biol 17: 5588-5597, 1997.

22. Pages G, Lenormand P, Allemain G, et al: Mitogen-activated protein kinase p42MAPK and p44MAPK are required for fibroblast proliferation. Proc Natl Acad Sci USA 90: 83198323, 1993.

23. Kerkhoff E and Rapp UR: Cell cycle targets of Ras/Raf signalling. Oncogene 17: 1457-1462, 1998.

24. Zhang W and Liu HT: MAPK signal pathways in the regulation of cell proliferation in mammalian cells. Cell Res 12: 9-18, 2002.

25. Hill CS, Wynne J and Treisman R: Serum-regulated transcription by serum response factor (SRF): a novel role for the DNA binding domain. EMBO J 13: 5421-5432, 1994.

26. Shaulian E and Karin M: AP-1 in cell proliferation and survival. Oncogene 20: 2390-2400, 2001.

27. Treinies I, Paterson HF, Hooper S, Wilson R and Marshall CJ: Activated MEK stimulates expression of AP-1 components independently of phosphatidylinositol 3-kinase (PI3-kinase) but requires a PI3-kinase signal to stimulate DNA synthesis. Mol Cell Biol 19: 321-329, 1999.

28. Smith MJ and Prochownik EV: Inhibition of c-jun causes reversible proliferative arrest and withdrawal from the cell cycle. Blood 79: 2107-2115, 1992.

29. Kovary K and Bravo R: The jun and fos protein families are both required for cell cycle progression in fibroblasts. Mol Cell Biol 11: 4466-4472, 1991.

30. Nishikura K and Murray JM: Antisense RNA of proto-oncogene c-fos blocks renewed growth of quiescent 3T3 cells. Mol Cell Biol 7: 639-649, 1987.

31. Guo YL, Kang B, Yang LJ and Williamson JR: Tumor necrosis factor-alpha and ceramide induce cell death through different mechanisms in rat mesangial cells. Am J Physiol 276: 390-397, 1999.

32. Lenczowski JM, Dominguez L, Eder AM, King LB, Zacharchuk CM and Ashwell JD: Lack of a role for Jun kinase and AP-1 in Fas-induced apoptosis. Mol Cell Biol 17: 170-181, 1997.

33. Van WC: Nuclear factor-kappaB in development, prevention, and therapy of cancer. Clin Cancer Res 13: 1076-1082, 2007. 
34. Guttridge DC, Albanese C, Reuther JY, Pestell RG and Baldwin AS: NF-kappaB controls cell growth and differentiation through transcriptional regulation of cyclin D1. Mol Cell Biol 19: 5785-5799, 1999.

35. Ghoda L, Lin X and Greene WC: The 90-kDa ribosomal S6 kinase (pp90rsk) phosphorylates the N-terminal regulatory domain of IkappaBalpha and stimulates its degradation in vitro. J Biol Chem 272: 21281-21288, 1997.

36. Barradas M, Monjas A, Diaz-Meco MT, Serrano M and Moscat J: The downregulation of the pro-apoptotic protein Par-4 is critical for Ras-induced survival and tumor progression. EMBO J 18: 6362-6369, 1999.
37. Qiu SG, Krishnan S, el-Guendy N and Rangnekar VM: Negative regulation of Par-4 by oncogenic Ras is essential for cellular transformation. Oncogene 18: 7115-7123, 1999.

38. Kato N, Yoshida H, Kioko OS, Kato J, Goto T, Otsuka M, Lan K, Matsushima K, Shiratori Y and Omata M: Activation of intracellular signaling by hepatitis $\mathrm{B}$ and $\mathrm{C}$ viruses: $\mathrm{C}$-viral core is the most potent signal inducer. Hepatology 32: 405-412, 2000.

39. Yen TS: Nuclear factor kappaB and hepatitis C - Is there a connection? Hepatology 31: 785-787, 2000. 